\title{
THE PERCEPTIONS OF EMERGENCY VEHICLE DRIVERS USING SIMULATION IN DRIVER TRAINING
}

\author{
Jeffrey T. Lindsey \\ Instructional Technology \\ University of South Florida \\ Estero, Florida, USA \\ E-mail: jtlindsey1@aol.com \\ Ann E. Barron \\ Instructional Technology \\ University of South Florida \\ Tampa, Florida, USA
}

\begin{abstract}
Summary: The number of accidents over the past decade involving emergency vehicles is a major concern for emergency service providers. This study assessed the perception of adding a driving simulator to a traditional training program. The sample population consisted of Emergency Medical Technician students attending the National EMS Academy in Lafayette, LA. The group self-scheduled which day they would attend the driving portion of the class. This resulted in 52 participants in the control group and 50 participants in the treatment group. The treatment group used a driving simulator prior to driving on the competency course.

Surveys were used to assess the emergency vehicle operators' perceptions of using a driving simulator as part of an emergency vehicle training course. The simulator allowed the treatment group to understand the course prior to actually driving the course. The control group thought the simulator would have afforded them the opportunity to learn the course before actually driving the course. Both groups thought the simulator should be a part of the driver training course, but did not see the simulator replacing actual driving experience. Emergency Medical Technician students in both the treatment and control group thought the simulator would improve their driving ability
\end{abstract}

\section{INTRODUCTION}

This research study focused on a population of emergency vehicle drivers who did not have any experience driving emergency vehicles. There are accidents even during training classes. On November 20, 2003, Collier County EMS crews in Florida were training on their new \$100,000 ambulance when it rolled over on its side after the driver lost control ("Medics injured in ambulance crash released from hospital," 2003). In many cases, the causes of accidents center around human error. A change, beginning with the training of emergency vehicle drivers, may be warranted. 


\section{Background of the Study}

Previous research has concluded that simulators can be effective tools in training programs. For example, the director of Penn State's anesthesia training has been studying the comfort level of residents when anesthetizing patients. He asks them how they feel about performing 40 tasks22 of which they practice on the simulator in the first three days of their training. On day four they move into the operating room and the confidence level of students intubating a patient rises from $55 \%$ to $75 \%$. For the 18 tasks they do not first practice on the simulator, confidence rises from $55 \%$ to $58 \%$ (Kiser, 2000). The effectiveness of flight simulators is referred to in many instances as Transfer Effectiveness Ratio (TER) (Why use simulation?-Return on investment, 2003). The literature suggests that military flight simulators have greater than 0.33 TERs, which is $59 \%$ of the tasks they use in training. This means that for every three hours spent in the simulator, one hour of actual flight time could be eliminated for $54 \%$ of the tasks (Why use simulation? - Return on investment, 2003). Additionally, the cost to operate a flight simulator is $5-20 \%$ of the cost of the aircraft. The Air Force Mobility Command is planning to replace up to $50 \%$ of the hours they conduct flight training with flight simulators. Lindsey (2004) also reported significant differences in performance by students who were trained with a simulator, as opposed to those who were not.

The purpose of this paper was to study the perceptions (rather than the performance) of students in an emergency vehicle drivers training course. Some of the students received training on a simulator; others received training via traditional methods only.

\section{METHOD}

\section{Research Design}

The qualitative research design of the study was phenomenological. Phenomenological methods are when a stimulus is presented to the participants and they are asked to describe what they perceive (Moghaddam, Walker, \& Harre, 2003). This study investigated the perceptions of students who engaged in a computer-based simulation training course for emergency vehicle drivers.

\section{Participants}

There were 122 participants registered to attend the emergency vehicle driver training course at the National EMS Academy in Lafayette, LA. The didactic session was conducted with 105 participants in attendance. The driving portion was conducted over the following five days, with 102 of the 105 who had attended the didactic portion driving the competency course. The group had self-scheduled which day they would attend the driving portion of the class. The participants were not aware that a simulator was scheduled to be part of the training for some on some of the days. This self-scheduling process resulted in 52 participants in the control group and 50 participants in the treatment group. 


\section{The Simulator}

The simulation used in the study was designed to allow the participant to maneuver an emergency vehicle through situations they are likely to encounter during a typical response. The treatment group received this portion of the program after they completed their first day of training and prior to driving on the competency course.

The design of the simulator emulated the driving competency course. This resulted in a near transfer learning environment for the participant. A near transfer is when the participant is placed into an environment very similar to the one in which they will be functioning in the real world (Alessi \& Trollip, 2001). They were required to drive through the competency course simulation at least twice. The first time an instructor provided individualized instruction, coaching the student through the process and illustrating the position and maneuvering of the vehicle through the aerial view that can be used with the simulator.

\section{Survey Instrument}

The investigator developed an instrument to survey the participants of this study. There were separate surveys for the control group and the treatment group. A panel of experts reviewed the survey for content-related validity. These experts consisted of individuals who have been trained to drive emergency vehicles by the investigator in a prior program. Revisions to the survey were made, based on input from the content experts.

\section{Qualitative Procedures}

At the end of the two-day session (including both classroom training and competency training), the entire sample was surveyed by the investigator, using the survey instrument developed for this study. The treatment group was queried about their opinions regarding their use of the simulator as part of the driver training program. Both groups were asked to offer their opinion of the value of a computer simulator to instruct emergency driving training. This information was categorized, examined for trends, and presented in a qualitative format.

\section{Qualitative Analysis}

The analysis of the data was used to identify any trends in responses from the surveys. The results were tabulated by the investigator without the use of a software program. The results of the survey were analyzed using a thematic approach. The first approach was to determine if those who used the simulator had positive opinions about the use of the simulator and if they were positive in their response to actually using the simulator as part of the driving program. In contrast, the perceptions of the control group (who did not use the simulator) were reviewed to see if they felt the simulator would have been beneficial to them in the training program. The investigator developed the themes based on the responses by the control and treatment groups. Using a written survey helped to avoid any bias on the part of the investigator.

Categories were determined a posteriori using an exploratory, variable-oriented analysis. Emergent themes were analyzed and quantified (Tashakkori \& Teddlie, 2003) for frequency analysis. The investigator used the "numbered nature of phenomena" (Sandelowski, 2001). 
Through computing the frequency with which each theme occurred in the data and expressing these frequencies as percentages, frequency or manifest effect sizes were obtained (Onwuegbuzie \& Teddlie, 2003).

\section{RESULTS}

This study investigated the emergency vehicle operators' perceptions of using a driving simulator as part of an emergency vehicle training course. Separate surveys were administered to the treatment group and control group. A thematic approach was used to analyze the responses to each of the questions. Each response was categorized into one theme for each group.

Describe how the simulator did or did not help you prepare you for the driving course. The treatment group was asked to describe how the simulator did or did not help them to prepare for the driving course. Four major themes were identified from the responses. The overwhelming theme was, "The simulator prepared [me] to drive and gain a better understanding of the competency course layout." The results are provided in Table 1.

Table 1. Thematic responses for "simulator preparing" treatment group

\begin{tabular}{|lc|}
\hline Theme & Percentage of respondents \\
\hline Positive & \\
\hline Prepare to drive/course layout knowledge & $82 \%$ \\
Easier than actual driving & $4 \%$ \\
\hline Negative & \\
\hline Did not help & $4 \%$ \\
\hline Unambiguous & \\
\hline No response & $10 \%$ \\
\hline
\end{tabular}

What is your opinion of using simulators to teach emergency vehicle operators to drive an emergency vehicle? The remaining questions were asked of both groups. The first question asked about their opinion of using simulators to teach emergency vehicle operators to drive an emergency vehicle. Although both groups answered the same question, the data and themes are presented separately for the treatment and control groups. Both groups thought the "simulator would be helpful." Other themes included "need both simulator and actual driving" and "actual driving is better." The results are provided in Table 2. 
Table 2. Thematic responses using simulator to teach driving.

\begin{tabular}{|lcc|}
\hline Theme & $\begin{array}{c}\text { Percentage of respondents } \\
\text { TREATMENT GROUP }\end{array}$ & $\begin{array}{c}\text { Percentage of respondents } \\
\text { CONTROL GROUP }\end{array}$ \\
\hline Positive & $50 \%$ & $79 \%$ \\
\hline Simulator helpful & $30 \%$ & \\
Need both simulator and actual driving & & \\
\hline Negative & $8 \%$ & $4 \%$ \\
\hline Simulator does not help & $4 \%$ & \\
Simulator needs to be harder & & $17 \%$ \\
Actual driving is better & $2 \%$ & \\
Easier in ambulance & & \\
\hline Ambiguous & $6 \%$ & \\
\hline No opinion & & \\
\hline
\end{tabular}

Do you feel the simulator was (would have been) beneficial as part of your training? The next question asked the treatment group if the simulator was a beneficial part of their driver training program and the control group if they thought the simulator would have been beneficial. The treatment group responded overwhelmingly $(82 \%)$ in favor that the simulator was beneficial in their training. The control group also responded in a very positive manner $(85 \%)$. The results are provided in Table 3.

Table 3. Thematic response to benefits of driver training program.

\begin{tabular}{|lcc|}
\hline Theme & $\begin{array}{c}\text { Percentage of respondents } \\
\text { TREATMENT }\end{array}$ & $\begin{array}{c}\text { Percentage of respondents } \\
\text { CONTROL }\end{array}$ \\
\hline Positive & $76 \%$ & \\
\hline Driving and course lay out & $2 \%$ & \\
Time to practice & $2 \%$ & $56 \%$ \\
It was fun & & $22 \%$ \\
Simulator provides more learning & & $4 \%$ \\
points & & $2 \%$ \\
Helped with vehicle dynamics & & $2 \%$ \\
Reduce penalty points & & \\
Simulator would be less stress & $8 \%$ & $8 \%$ \\
Simulator would be safer & $2 \%$ & $2 \%$ \\
\hline Negative & & $4 \%$ \\
\hline Not like actual driving & & \\
Confusing & $10 \%$ & \\
Did ok without simulator & & \\
\hline Ambiguous & & \\
\hline No response & & \\
\hline
\end{tabular}

Should the simulator be incorporated into the driver training program? Both groups were asked if a driving simulator should be incorporated into the emergency vehicle driving program. The treatment group responded $(86 \%)$ in favor of incorporating the simulator in the emergency 
vehicle driver program. The control group responded (87\%) in favor of including the simulator as part of the emergency vehicle driving program. The results are provided in Table 4.

Table 4. Thematic response to incorporating simulator into driver training program

\begin{tabular}{|lcc|}
\hline Theme & $\begin{array}{c}\text { Percentage of respondents } \\
\text { TREATMENT }\end{array}$ & $\begin{array}{c}\text { Percentage of respondents } \\
\text { CONTROL }\end{array}$ \\
\hline Positive & $64 \%$ & $23 \%$ \\
\hline Prepares a person to drive & $8 \%$ & $5 \%$ \\
Excellent tool & $6 \%$ & $2 \%$ \\
Safe alternative & $2 \%$ & $33 \%$ \\
Cost effective & & $8 \%$ \\
Better understanding of competency course & & $5 \%$ \\
More training & & $2 \%$ \\
Different insight & $2 \%$ & \\
More practice & & $2 \%$ \\
\hline Negative & $2 \%$ & \\
\hline Need to use simulator longer & $2 \%$ & $20 \%$ \\
Actual driving better & & \\
Simulator is unreal & $14 \%$ & \\
Need it to be size of ambulance & & \\
\hline Ambiguous & & \\
\hline No response & & \\
\hline
\end{tabular}

Should the simulator be used instead of the competency course in the driver training program? The final question asked both groups if the simulator should be used instead of the competency course. The treatment group responded overwhelmingly $(90 \%)$ that the simulator should not replace the driving portion of the emergency vehicle driver training program. The majority theme was, "actual driving experience was needed and nothing could replace the actual driving." The control group also responded overwhelmingly ( $83 \%)$ that the simulator should not replace the driving portion of the emergency vehicle driver training program. The majority theme for this group was the same as the treatment group, "actual driving experience was needed and nothing could replace the actual driving." The results are provided in Table 5.

Table 5. Thematic response to whether the simulator should be used instead of the competency course.

\begin{tabular}{|lcc|}
\hline Theme & $\begin{array}{c}\text { Percentage of respondents } \\
\text { TREATMENT }\end{array}$ & $\begin{array}{c}\text { Percentage of respondents } \\
\text { CONTROL }\end{array}$ \\
\hline Positive & & $62 \%$ \\
\hline Actual driving also needed & $80 \%$ & $2 \%$ \\
Simulator less stressful & $4 \%$ & $4 \%$ \\
More time on simulator & & $20 \%$ \\
\hline Negative & $4 \%$ & $12 \%$ \\
\hline Competency course did not help - simulator only & $4 \%$ & \\
Simulator did not help - actual driving only & & \\
\hline Ambiguous & $8 \%$ & \\
\hline No response & & \\
\hline
\end{tabular}




\section{CONCLUSION OF FINDINGS}

The implications of the findings of this study illustrate that there is a perception that using a simulator has a positive effect on driving ability. The participants also expressed an overall positive attitude toward using the simulator as part of emergency vehicle driver training. A study conducted by Brock, Jacobs, and Buchter (2001) asked participants about the satisfaction of using driver simulators to train to drive a bus. There was a high level of satisfaction $(92 \%)$ reported from all locations of respondents for training purposes. Furthermore, $58 \%$ of the respondents perceived that the simulator was more effective than traditional training methods.

Simulators would be beneficial to include in the emergency vehicle driver training program for a couple of reasons. The first benefit is the cost of the simulator versus the cost of an actual ambulance. The simulator used in this study retails for $\$ 70,000$ (Craft, 2004). As noted in an article in the Fort Myers News Press, the cost of an ambulance is about $\$ 100,000$ ("Medics injured in ambulance crash released from hospital," 2003). If an ambulance is damaged during a training evolution, there is a cost to repair the damage and a time period for which the ambulance is not available to respond on calls. If a driver "wrecks" an ambulance on the simulator, no actual damage occurs. In addition, if a driver is involved in an ambulance accident, he or she may be injured; whereas, injury is unlikely to occur in a simulator.

In addition to the cost of the emergency vehicle, there are many other costs associated with conducting a competency course training program on a training site. There is the cost of the instructors. At least two instructors should be on the competency course at all times, along with a safety officer. In contrast, an instructor is not required to be present when the driver is training on a simulator. Additionally, the simulator can be used at any time of any day. In order to set up the driving course, it takes approximately $1 \frac{1}{2} 2$ hours to lay out and mark the course. There are 100 cones that need to be used, and these orange traffic cones typically are damaged and destroyed over time from the ambulances running over them. There were approximately 15 traffic cones destroyed during this study.

The results of surveying both groups answered the question of the emergency vehicle operators' perceptions of using a driving simulator as part of an emergency vehicle training course. The simulator allowed the treatment group to understand the course prior to actually driving the course. The control group thought the simulator would have afforded them the opportunity to learn the course before actually driving it. Both groups thought the simulator needs to be a part of the driver training course, but do not see the simulator replacing actual driving experience. In both instances, the emergency vehicle operators thought the simulator would improve their driving ability.

\section{REFERENCES}

Alessi, S. M., \& Trollip, S. R. (2001). Simulations. In Multimedia for learning (pp. 213-269). Needham Heights, MA: Pearson Education Company.

Brock, J. F., Jacobs, C., \& Buchter. (2001). Design of a guidebook for the acquisition of and use of driving simulators for training transit bus operators. Proceedings of the First International Driving Symposium on Human Factors in Driver Assessment, Training and Vehicle Design. Aspen, CO, p. 339-344. 
Craft, F. (2004). Discussion on cost of Road Safety simulator. Lafayette, LA.

Kiser, K. (2000). Operation learning. Inside technology training (May 2000), 22-22.

Lindsey, J. (2004). The effects of Computer Simulation and Learning Styles on Emergency Vehicle Drivers' Competency in Training Course. Dissertation. University of South Florida.

Medics injured in ambulance crash released from hospital. (2003, November 20). News Press.

Moghaddam, F. M., Walker, B. R., \& Harre, R. (2003). Cultural distance, levels of abstraction, and the advantages of mixed methods. In A. Tashakkori \& C. Teddlie (Eds.), Handbook of mixed methods in social and behavioral research (pp. 111-134). Thousand Oaks: Sage Publications, Inc.

Onwuegbuzie, A. J., \& Teddlie, C. (2003). A framework for analyzing data in mixed methods research. In A. Tashakkori \& C. Teddlie (Eds.), Handbook of mixed methods in social \& behavioral research (pp. 351-384). Thousand Oaks, CA: Sage Publications, Inc.

Sandelowski, M. (2001). Real qualitative researches don't count: The use of numbers in qualitative research. Research in nursing \& health, 24, 230-240.

Tashakkori, A., \& Teddlie, C. (2003). Handbook of mixed methods in social \& behavioral research. Thousand Oaks, CA: Sage Publications, Inc.

Why use simulation? - Return on investment. (2003). Retrieved December 18, 2003, from http://www.trainingsystems.org/publications/simulation/roi_effici.cfm 